\title{
Art in Wittgenstein's Philosophy of Language
}

\author{
Zhentao Chen
}

\author{
Philosophy Department, Grinnell College, Grinnell 50112, The United States, chenzhen2@grinnell.edu
}

\begin{abstract}
Early Wittgenstein and Later Wittgenstein each developed a system of philosophy of language. They both offer a solution to the question of the meaningfulness of language. Later researchers are interested in whether and how Wittgenstein's philosophy of language can function to solve philosophy of other disciplines. Aesthetics and art are one of the major focuses. This paper summarizes possible Wittgensteinian understandings and interpretations of art. Keywords: Wittgenstein, art, language game, Tractatus, sayable, showable.
\end{abstract}

\section{INTRODUCTION}

Wittgenstein wrote little on the subject of art. His lectures, instead, are the main position of the discussion of art. However, since most of his philosophical writings focus on meaningfulness, perception, and sense, it is feasible to find a way for art to enter his philosophy of language. Nevertheless, there is also a theory stressing that art cannot Wittgenstein's theory of language. A review of that theory needs to be done.

\subsection{Related Work}

According to Brooke Lundquist in Wittgenstein and Aesthetics: What is the Language of Art [1], art and language are not parallel. It is not because that art is a private language, but it is unsayable. Since Wittgenstein in Tractatus states that what is unsayable must remain silent, art cannot enter Wittgenstein's philosophy of language. However, because people live in a world where things always refer to and rely on language, a falsehood of understanding art in the sense of language and translation is formed.

The main mistake of Lundquist's argument is the wrong use of unsayable. In Tractatus [2], Wittgenstein draws a division between sayable and unsayable. What can be said must be pictures of possible states of affairs. Possible states of affairs mean that what is sayable must be truth and falsehood bivalence. On the contrary, what is unsayable are not contingent, but tautology or contradiction. What is unsayable are logical propositions, not part of the world. In other words, they can only be shown by what is sayable. The nature of logical truth and falsehood should be understood internally and proved within the language system. Wittgenstein's division of sayable and unsayable focuses on the topic of logical propositions and states of affairs, not simply as the name unsayable suggests. Art should enter the section of what is sayable since it is not unsayable. Art is not logical propositions, tautology, or contradiction. Furthermore, to say that art is sayable, it must be proved that art can be expressed, pictured, and said, determined by that language makes these possible. Since Lundquist is directly against understanding art in the sense of language, how art can enter Wittgenstein's theory of language is the next issue to be considered.

\section{EARLY WITTGENSTEIN IN TRACTATUS}

Wittgenstein makes language feasible to have meaning in Tractatus by offering the picture theory solution. Similar to representationalism, the proposition is the carrier of the meaning by picturing a possible combination of simple objects or states of affairs. Wittgenstein proposes that "We picture facts to ourselves." (Tractatus, 2.1) Pictures carry meaning because they show how possible combinations of simple objects or states of affairs look like to us. It is the model of reality, which is a way of representing. Logical form, which is what the picture has in common with what it depicts, guarantees such determinate representational correlation because it ensures that the picture has the possibility of combining its elements (simple names) as the possible state of affairs it pictures does of combining its elements (simple objects). Based on logical form, pictures of the simple objects, in reality, can combine with each other to form more complex ones in a certain restricted combining way and in a certain range of components. A proposition, which is a linguistic picture, is also a representational situation where a thought finds an expression perceived by the senses. It is an expression of the general process of a wordy sentence in the representational relation to reality. Hence, it also follows the setting of pictures. In the range of logical space, simple names, which are the representation of simple 
objects, combine with each other, forming a more complex elementary proposition. Different from Frege's idea, the way how linguistic propositions carry meaning lies neither in the sense nor the reference, but simply the logical form, namely the possibility of expressing the corresponding possible states of affairs in reality. However, the actual truth or falsity of such picturing still remains for further examination of comparing the proposition with the actual states of affairs.

\subsection{Early Wittgenstein and Art}

In Wittgenstein's quasi-representationalism account in Tractatus, he justifies that language is meaningful in a pictorial sense. Arts like paintings and architecture can, therefore, enter Wittgenstein's philosophy of language because the characteristics of arts share similarities with those of language in Tractatus. One typical and ancient case is ancient Egyptian symbols. The important symbols are sorted as Ankh, Djed, Was Scepter, Numbers, Scarab, Tjet, Crook \& Flail, Shen, Udjat Eye, Sesen, and BenBen [3]. In the illiterate society, all of them serve as the carriers of representations of the physical world. The understanding of the physical world is symbolized through images in art and architecture for the peasant farmers, who cannot read the literature, poetry, or hymns, to read through the symbols. Such primitive forms of art originally function as the alternative of language. Similar to language, they represent the physical world by picturing the possible combinations of states of affairs and simple objects. The main purpose of such representation is to carry meaning within the art itself to tell a story. Different designs and ways of depicting express different stories and contents. Besides the primitive forms of art like ancient Egyptian symbols, art in the broader sense also can enter the Tractarian theory of language. In The Spectator in the Picture [4], Robert Hopkins summarizes that Richard Wollheim differentiates between depictive and expressive content in art. Depictive art is a matter of what a piece of artwork depicts, while expressive art is that of what a piece of artwork expresses emotions and moods. Hence, the former forms of depictive art like ancient Egyptian symbols also follow the logical form in Tractatus, which is the possibility of expressing the corresponding states of affairs in the real world. Therefore, there are streams of art that can completely enter early Wittgenstein's philosophy of language in Tractatus.

\section{LATE WITTGENSTEIN IN PHILOSOPHICAL INVESTIGATIONS}

Later Wittgenstein notices that the last account of solipsism in Tractatus bears doubt because it oversights the practical uses of language. Thereupon, in his later work, Philosophical Investigations [5], he reverses the direction of reasoning by starting with the discussion of the particularity of language, stating that like tools, the meaningfulness of language is understood in its practices and there is no shared extensive essence that makes language be understood in the same way in different circumstances. Instead of proposing that the shared essence of all propositions, the possibility of representing or picturing the possible states of affairs, makes language meaningful, Wittgenstein holds that the complicated network of similarities between all language games makes language meaningful. In other words, there is no such thing as one common essence of language, but simply loose family resemblance. He makes the claim in the opposite to Tractatus by starting from contingent practical uses and providing a contextualist account of the language. He can, therefore, set out space for the later refutation of private language argument from the beginning. Based on contextualism about language meaning, Wittgenstein further develops the whole system of language as language games in a new sense of carrying meaning in accordance with the linguistic community. Still, Wittgenstein summarizes that language neither has its meaning from entering the language game, nor vice versa. Before entering the cultural and social backgrounds and language games, language has a normative notion within itself. The normative notion can be understood in certain cultural practices or forms of life when one becomes an insider of such causal relation by learning. It is within the social practice, namely, the form of life, the indeterminacy of meaning has its objective standing point. "It is in their language that human beings agree. This is agreement not in opinions, but rather in form of life." (Philosophy Investigations, ss.241) Such normative notion is not based on statistical agreement, but on partaking in the form of life. Within such conditions of social practice, the determinacy of meaning is legitimate because of the shared understanding of the community and how language is to be used. A new theory of language understood in language games and forms of life is proposed by later Wittgenstein in Philosophical Investigations.

\subsection{Late Wittgenstein and Art}

The next major task is to examine whether and what kind of art can enter language games and forms of life. Again, in The Spectator in the Picture, Hopkins quotes Wollheim in Painting as an Art [6] that some pictures, (1) represent (have as part of their content) [101] (2) someone viewing the depicted scene (3) more or less from the point from which it is depicted [102,183] (4) with a repertoire of psychological states and dispositions to think, act and feel - (a) at a minimum that repertoire involved in being an embodied viewer [130], but perhaps (b) some more distinctive psychology (5) who is distinct from the person in the gallery looking at the picture [1835], but (6) with whom that person imaginatively identifies, with the result (7) that the viewer of the picture 
is left responding to the picture differently, in ways both perceptual

and affective, and thus understanding the picture in a new way. [129,183] A common hesitation about art, therefore, arises here. There is possibly an "internal spectator" that brings different possibilities of understanding to viewers. Art, therefore, might fall in the domain of private language in Philosophical Investigations, which Wittgenstein rejects. Private language is the "idea of idea." The meaning is to be understood in terms of associated ideas in the mind of the speaker. Private language cannot be understood by others, so an account of communication cannot be reached. Language does not have meaningfulness accordingly. Besides, there is a deeper problem that one cannot understand one's own language. When one uses a specific term, one must understand it associated with the corresponding experience. It sets up a kind of criteria of correctness, which requires one to recall the old experience and check whether the current one is similar. However, Wittgenstein suggests that this internal check is not checking at all. The temptation to think of the current experience and use the corresponding term is to think of the original experience that constitutes the meaning in the first place. That process cannot be a check because doing so does not check anything. It is doing the same thing over again, presupposing that they are similar but not recalling. Since the check is useless, then one cannot one's own private language either. After all, private language is meaningless. Nevertheless, neither depictive nor expressive art falls into the private language issue if art is put in the same reasoning of language games and forms of life. When the artist creates a piece of artwork, he or she puts the original normative notion into it without pointing it out. When the artwork is viewed by the public, it enters the language games and forms of life. People's cultural and social backgrounds determine the way of viewing the piece of artwork. People develop agreements from forms of life to interpret it. People use language to understand it and talk about it with others. The agreement of the normative notion of art, therefore, is built and understood gradually based on partaking in life.

\section{CONCLUSION}

In summary, art and language are parallel. They share the great similarity in both early and later Wittgenstein's philosophy of language. Besides, art does not fall into the key problems that Wittgenstein rejects in Tractatus and Philosophical Investigations. The suspicion addressed by Lundquist can be solved by placing art in the position of language in Wittgenstein's philosophy of language. Furthermore, as Wittgenstein proposes in Lectures and Conversations on Aesthetics, Psychology, and Religious Belief [7], "An entirely different game is played in different ages." Art evolves as the time periods change.
When art becomes more daily and accessible for the public, the games of art are even closer to language games. When street arts and performance arts like standup comedies and comic dialogues enter the stage of art, their games of art overlap the language games.

It is possible that some may doubt that such a logically normative and scientific view of art can destroy the beauty and aesthetics that reside in the artwork. However, Wittgenstein's language game theory is itself a relaxed system that involves multi-cultural factors. The space for romanticism and aesthetics in art is within the loose game system itself. Moreover, Wittgenstein himself states in Philosophical Investigations that he does prepare for the later indeterminacy of giving any certain solution to the meaningfulness problem. $\mathrm{He}$ denies the necessity of his language game theory because it is a philosophical solution to the meaning and language relation with the discussion of philosophy. He argues that his solution is always possible to receive further doubts and there are other possible answers, indicating that there is no certain necessary solution, but barely possible therapy. A similar response can be adopted in the discussion of art in this article. Putting art and its meaningfulness into Wittgenstein's language theory is simply a possible therapy without complete credit. It offers a solution, but not necessarily of absolute certainty.

\section{REFERENCES}

[1] Lundquist, B. (1999, May). Wittgenstein and Aesthetics: What is the Language of Art? https://gustavus.edu/philosophy/Brooke.html.

[2] Wittgenstein, L., Pears, D., \& McGuinness, B. (2002). Tractatus logico-philosophicus. Routledge.

[3] Mark, J. J. (2017, February 10). Ancient Egyptian Symbols. World History Encyclopedia. https://www.worldhistory.org/article/1011/ancientegyptian-symbols/.

[4] Hopkins, R. (1970, January 1). The Spectator in the Picture. White Rose Research Online. https://eprints.whiterose.ac.uk/10340/.

[5] Wittgenstein, L. (1968). Philosophical investigations. Blackwell.

[6] Wollheim, R. (1987). Painting as an art. Princeton University Press.

[7] Barrett, C., \& Wittgenstein, L. (1966). L. Wittgenstein: lectures and conversations on aesthetics, psychology and religious belief. Blackwell. 